13

\title{
Электронно-стимулированная десорбция атомов цезия с графена на иридии
}

\author{
(С Ю.А. Кузнецов, Е.В. Рутьков, Н.Р. Галль
}

Физико-технический институт им. А.Ф. Иоффре РАН, Санкт-Петербург, Россия

E-mail: kuznets@ms.ioffe.ru

Поступило в Редакцию 15 марта 2018 г.

Впервые прямым методом обнаружена электронно-стимулированная десорбция (ЭСД) атомов Cs с поверхности графена на металле (иридии). Измерения выполнены времяпролетным методом с помощью детектора на основе поверхностной ионизации. Порог появления выхода ЭСД атомов Cs при температуре поверхности $160 \mathrm{~K}$ равен $20 \mathrm{eV}$, также наблюдается дополнительный пик выхода ЭСД атомов Cs при энергии облучающих электронов $56 \mathrm{eV}$. Наблюдаемая ЭСД атомов Cs c графена связывается с неметаллической природой пленки графена на поверхности металла.

DOI: 10.21883/PJTF.2018.12.46298.17295

Облучение электронами поверхности твердого тела с адсорбированными атомами металлов может приводить к электронностимулированной десорбции (ЭСД) нейтральных адатомов металлов, если время жизни возбужденного состояния связи адсорбированная частица-поверхность достаточно велико для разрыва этой связи и удаления частицы от поверхности. Физические основы ЭСД рассмотрены в работах [1-7].

На поверхности металла возбужденное состояние адсорбированного атома оказывается очень короткоживущим за счет быстрого ухода возбужденного электрона в зону проводимости подложки, и поэтому ЭСД нейтральных адатомов металлов на металлах не наблюдается [1]. Слой же диэлектрика (или полупроводника) на поверхности металла существенно увеличивает время жизни возбужденного состояния $[1,2]$, и возбужденный атом имеет конечную вероятность десорбироваться с поверхности. В этих условиях ЭСД адсорбированных атомов металлов имеет место. Поэтому уже само наличие ЭСД адатомов металлов в 
той или иной адсорбционной системе традиционно рассматривается как прямое свидетельство неметаллической природы околоповерхностной области подложки $[1,2]$. В качестве изолирующей прослойки между металлическим адсорбатом и металлической поверхностью ранее нами использовались адсорбированные слои кислорода $[4,5]$, германия [6] и интерметаллид золота [7]. На таких поверхностях наблюдается ЭСД атомов $\mathrm{Li}[4], \mathrm{K}[4,5], \mathrm{Na}[4], \mathrm{Cs}[4-7]$ и $\mathrm{Ba}[4]$.

$\mathrm{B}$ настоящей работе в качестве слоя, отделяющего металлическую подложку от адсорбированных атомов, был выбран слой графена на $\operatorname{Ir}(111)$. Электронные свойства графена на металлах до конца не исследованы, и, возможно, опыты по изучению ЭСД атомов с него помогут прояснить эту картину. Следует отметить, что в литературе до сих пор работы по ЭСД с графена (тем более с применением прямых методов наблюдения) практически отсутствуют [8-10].

Задача данной работы состоит в экспериментальном исследовании возможности получения ЭСД атомов с поверхности графена на металле. На наш взгляд, это должно стать важным аргументом в рассмотрении вопроса о природе электронных свойств графена в контакте с металлической поверхностью. Мы использовали атомы Cs, свойства которых при ЭСД на других системах были многократно изучены ранее [4-7].

Измерения выполнены времяпролетным методом при импульсном облучении мишени электронами в сверхвысоковакуумной установке „Спектрометр ЭСД“, давление остаточных газов в которой не превышало $5 \cdot 10^{-10}$ Torr. Экспериментальный прибор и методика измерений подробно описаны ранее [11]. В качестве подложки использовалась текстурированная иридиевая лента размером $64 \times 1 \times 0.02 \mathrm{~mm}$ с преимущественным выходом на поверхность грани (111) с работой выхода $е \varphi=5.75 \mathrm{eV}[12]$. Система графен-иридий хорошо изучена в наших работах [12-14] и является традиционной при исследовании графена на поверхности металлов [15-18]. Это связано с уникальными свойствами иридия: он единственный из металлов не растворяет адсорбированный углерод вплоть до $T \sim 2100 \mathrm{~K}$, а пленки графена на иридии термостабильны до высоких температур $\sim 1800 \mathrm{~K}$. Графен на $\operatorname{Ir}(111)$ формировался стандартным способом - экспозицией нагретого до $T=1700 \mathrm{~K}$ иридия в парах бензола $\left(p_{\mathrm{C}_{6} \mathrm{H}_{6}} \sim 10^{6} \mathrm{Torr}\right)$ : молекулы бензола разваливались на нагретом металле, водород десорбировался, а атомы углерода образовывали островки графена, которые росли по площади, сливались и на конечном этапе объединялись в сплошную 
пленку графена $[12,13]$. На графене молекулы бензола не диссоциируют, и процесс роста пленки „автоматически“ ограничивается одним слоем графена. С помощью сканирующаей туннельной микроскопии убедительно показано, что на поверхности сформировался сплошной слой графена $[19,20]$. Графеновая пленка существенно понижает работу выхода поверхности до $е \varphi=4.45 \mathrm{eV}[12]$.

Цезий напылялся на мишень из прямонакального испарителя путем термического разложения хроматов цезия. Концентрация цезия на поверхности определялась по времени $t$ напыления постоянным потоком. Абсолютная калибровка потока $v$ атомов Cs производилась по измерению ионного тока $I_{\mathrm{Cs}}^{+}$, полученного путем поверхностной ионизации атомов $\mathrm{Cs}$ на $\operatorname{Ir}(111)$ при $T>800 \mathrm{~K}$. В этом случае имели место стопроцентная ионизация атомов и практически полный сбор ионов на коллектор. Как следует из формулы Саха-Ленгмюра, в случае „легкой“ ионизации, например, Cs на $\operatorname{Ir}(111) I_{\mathrm{Cs}}^{+}=e v S$, где $e-$ заряд электрона, $S$ - площадь эмитирующей поверхности [21].

Нагрев ленты осуществлялся электрическим током, а ее температура в области высоких $T$ определялась с помощью оптического микропирометра, а в области низких $T$ - путем экстраполяции этой зависимости к комнатной температуре. Лента могла охлаждаться и поддерживаться при заданной температуре в диапазоне $160-300 \mathrm{~K}$ путем изменения скорости пропускания через полые токовводы газообразного азота, который предварительно охлаждался в медной трубке, погруженной в жидкий азот. Температура ленты в этом диапазоне определялась по температурной зависимости электрического сопротивления.

Источником электронов в методе ЭСД служила вольфрамовая нить диаметром $0.15 \mathrm{~mm}$, нагретая до $T=1600 \mathrm{~K}$. Стационарная плотность тока бомбардирующих электронов не превышала $10^{-6} \mathrm{~A} / \mathrm{cm}^{2}$ при ускоряющем напряжении $\leqslant 100 \mathrm{~V}$ и поэтому не вызывала заметного нагрева мишени.

Десорбирующиеся при электронном облучении мишени атомы Cs проходили ряд коллимационных щелей, на которые подавались положительные тормозящие потенциалы, чтобы „отсечь“ теоретически возможную ионную составляющую потока десорбирующихся атомов Cs. Нейтральный цезий поступал в специальный технический узел, содержащий нагретую до $T=1800 \mathrm{~K}$ вольфрамовую ленту размером $70 \times 2 \times 0.01 \mathrm{~mm}$. На вольфрамовой ленте атомы Сs ионизовались (поверхностная ионизация) и десорбировались в виде ионов $\mathrm{Cs}^{+}-$

Письма в ЖТФ, 2018, том 44, вып. 12 


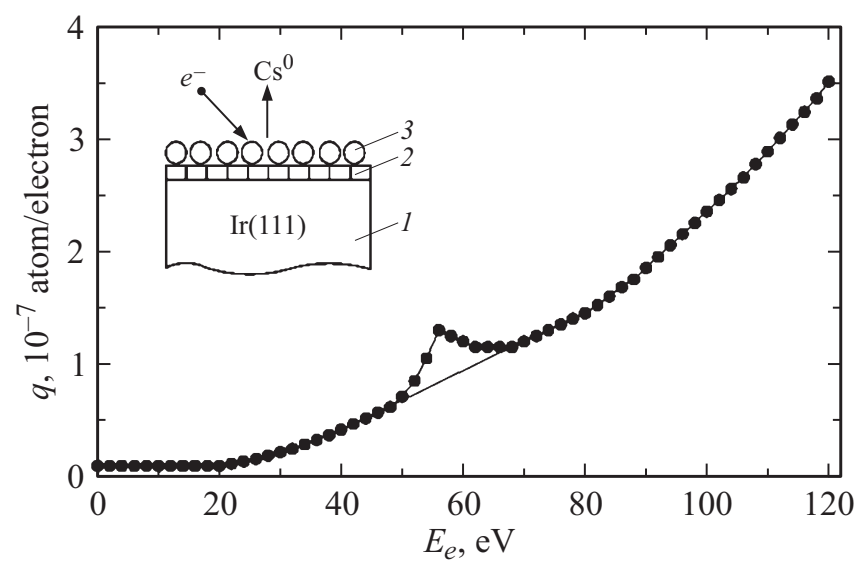

Рис. 1. Выход атомов Cs при ЭСД из слоя цезия, нанесенного на иридий, покрытый графеном, в зависимости от энергии облучающих электронов при температуре $160 \mathrm{~K}$. Концентрация нанесенного цезия $2.0 \cdot 10^{14}$ atom $/ \mathrm{cm}^{2}$. На вставке - упрощенная иллюстрация системы цезий, адсорбированный на графене при $160 \mathrm{~K}: 1$ - подложка $\operatorname{Ir}(111), 2$ - слой графена, 3 - атомы Cs на поверхности графена.

случай „легкой“ ионизации [21], когда атомы Cs десорбировались в виде ионов $\mathrm{Cs}^{+}$, которые регистрировались и анализировались коллекторной системой [11].

Известно, что атомы Cs даже при комнатных температурах адсорбируются на графеновой пленке на иридии, накапливаясь как на поверхности, так и под слоем графена примерно в равных концентрациях, близких к монослойной [22,23]. Для упрощения ситуации цезий наносился на графен при низкой температуре $160 \mathrm{~K}$, чтобы минимизировать влияние интеркалированного цезия на процессы ЭСД (вставка на рис. 1).

ЭСД атомов характеризуется величиной выхода $q$, равной отношению плотности десорбирующегося потока атомов к плотности потока электронов, возбуждающих ЭСД. На рис. 1 представлена зависимость выхода $q$ атомов Cs при ЭСД из слоя цезия, нанесенного на иридий, покрытый графеном, от энергии электронов. В данном опыте концентрация нанесенного цезия составляла $n_{\mathrm{Cs}}=v t=2.0 \cdot 10^{14}$ atom $/ \mathrm{cm}^{2}$. 
Видно, что выход атомов Cs имеет порог $20 \mathrm{eV}$. При увеличении же энергии облучающих поверхность электронов выход возрастает нелинейно. Также отчетливо наблюдается дополнительный пик выхода ЭСД атомов Cs при энергии облучающих электронов $56 \mathrm{eV}$.

Как уже указывалось выше, основы ЭСД рассмотрены в работах [1-7]. Опираясь на эти работы, можно отметить, что основным каналом ЭСД в данной адсорбционной системе видится образование (под действием электронного облучения поверхности) дырки на остовном уровне углерода $2 s$ с энергией $\sim 18 \mathrm{eV}$ [24], которая определяет порог появления выхода ЭСД атомов Cs и плавное его увеличение с дальнейшим ростом энергии электронов. Адатом Cs на поверхности графена находится в заряженном состоянии, т.е. в виде иона $\mathrm{Cs}^{+}$, поскольку потенциал ионизации цезия $3.89 \mathrm{eV}$ много меньше работы выхода графена. Дырка на уровне углерода $2 s$ заполняется электроном с более высоко лежащего уровня, вызывая оже-процесс; оже-электрон может быть захвачен адсорбированным ионом $\mathrm{Cs}^{+}$, нейтрализуя его, и возбужденный атом Cs покидает поверхность. Отметим, что в работе [5], в которой изучалась ЭСД атомов Cs c окисленного молибдена, порог появления выхода ЭСД наблюдался при $24 \mathrm{eV}$, что соответствует возбуждению уровня $2 s$ кислорода [25].

Появление дополнительного пика выхода ЭСД атомов Cs можно связать с оже-процессами возбуждения остовных уровней иридия $5 p_{3}$ и $4 f_{7}$ с энергией 53 и $62 \mathrm{eV}$ соответственно [25]. Аналогичные опыты на других диэлектрических поверхностях, например на окисленном молибдене, показали наличие дополнительных пиков выхода ЭСД атомов Cs c энергиями 40 и $70 \mathrm{eV}$ [5], что соответствовало возбуждению остовных уровней молибдена $4 p$ и $4 s$ соответственно [25].

Ответим на важный вопрос: как меняется выход ЭСД атомов Cs c графена при изменении концентрации нанесенного цезия? На рис. 2 представлена зависимость выхода атомов Cs при ЭСД из слоя цезия, нанесенного на иридий, покрытый графеном, от концентрации нанесенного цезия при температуре $160 \mathrm{~K}$ для энергии облучающих поверхность электронов $80 \mathrm{eV}$. Видно, что с ростом концентрации нанесенного цезия выход растет практически линейно, достигает максимума при концентрации $4.0 \cdot 10^{14}$ atom $/ \mathrm{cm}^{2}$, а затем спадает до уровня шума. Величину концентрации нанесенного цезия $4.0 \cdot 10^{14}$ atom $/ \mathrm{cm}^{2}$ в наблюдаемом максимуме выхода можно соотнести, видимо, с монослоем цезия на графене при $160 \mathrm{~K}$ [23]. Спад выхода ЭСД атомов Сs при

Письма в ЖТФ, 2018, том 44, вып. 12 


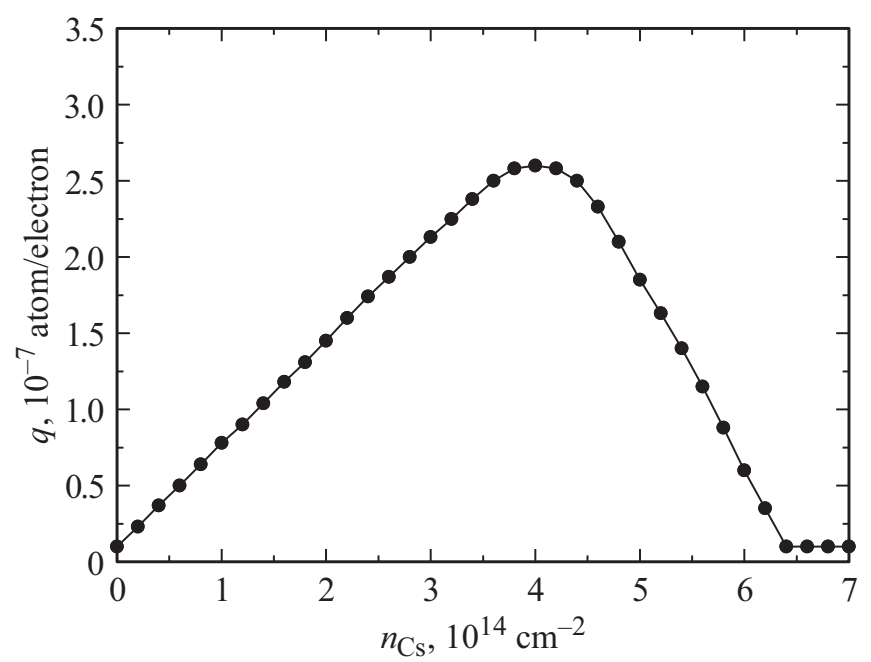

Рис. 2. Выход атомов Cs при ЭСД из слоя цезия, нанесенного на иридий, покрытый графеном, в зависимости от концентрации нанесенного цезия при температуре $160 \mathrm{~K}$ для энергии облучающих электронов $80 \mathrm{eV}$.

концентрациях нанесенного цезия, бо́льших, чем монослойная, можно связать с металлизацией слоя цезия.

Обсудим механизм процесса. Имеется ряд свидетельств в пользу неметаллической природы пленки графена на иридии, а скорее всего, и на других металлах. Так, показано, что работа выхода графена на $\operatorname{Re}(1010)$ растет по мере роста числа слоев $m$ от $4.30 \mathrm{eV}(m=1)$ до $4.70 \mathrm{eV}(m=10)$, и ее величина стабилизируется при толщине пленки порядка десяти слоев. В отличие от графена в хемосорбированном при $T=300 \mathrm{~K}$ углероде, например, на $\operatorname{Ir}(111)$ работа выхода стабилизируется при толщине пленки порядка одного слоя $[12,13]$. Зависимость работы выхода поверхности от толщины адсорбированной пленки в пределах десятков-сотен атомных слоев характерна для диэлектрических пленок [26].

В другой работе было обнаружено, что графеновая пленка на металлах толщиной до десяти слоев не поглощает излучение в оптическом диапазоне и не влияет на температуру образца [13]. При бо́льших 
толщинах графеновая пленка существенно влияет на истинную и яркостную температуры образца при неизменной подводимой мощности. Например, в случае пленки графена на $\mathrm{Rh}(111)$ толщиной $m \sim 80$ слоев истинная температура образца уменьшается на $\Delta T \sim 400 \mathrm{~K}[13,27]$. Полученные результаты показывают, что тонкие пленки графена на металле в диапазоне толщин от $m=1$ до $m=10$ слоев ведут себя как диэлектрики.

Таким образом, эксперименты с ЭСД атомов Cs c графена также подтверждают развиваемые выше представления. Графен на металле, по крайней мере в опытах по ЭСД, ведет себя как диэлектрик, хотя механизм ЭСД атомов Cs с графена на $\operatorname{Ir}(111)$ до конца не ясен.

\section{Список литературы}

[1] Ageev V.N. // Progr. Surf. Sci. 1994. V. 47. N 1-2. P. 55-203.

[2] Madey T.E. // Surf. Sci. 1994. V. 299-300. P. 824-836.

[3] Menzel D. // Surf. Interf. Anal. 2006. V. 38. P. 1702-1711.

[4] Ageev V.N., Kuznetsov Yu.A., Potekhina N.D. // Surf. Sci. 1996. V. 367. N 1. P. 113-127.

[5] Ageev V.N., Kuznetsov Yu.A., Madey T.E. // Surf. Sci. 1997. V. 390. N 1-3. P. $146-151$.

[6] Ageev V.N., Kuznetsov Yu.A., Madey T.E. // Surf. Sci. 2006. V. 600. N 10. P. 2163-2170.

[7] Ageev V.N., Kuznetsov Yu.A., Potekhina N.D. // J. Phys.: Condens. Matter. 2010. V. 22. N 8. P. 084005 (1-9).

[8] Krasheninnikov A.V., Nordlund K. // J. Appl. Phys. 2010. V. 107. N 7. P. 071301.

[9] Guo L., Chen X., Wang L., Cao S., Bai X., Zhang C., He Y., Gao H. // Key Eng. Mater. 2013. V. 562-565. P. 1069-1074.

[10] Bachmatiuk A., Dianat A., Ortmann F., Quang H.T., Cichocka M.O., GonzalezMartinez I., Fu L., Rellinghaus B., Eckert J., Cuniberti G., Rümmeli M.H. // Chem. Mater. 2014. V. 26. N 17. P. 4998-5003.

[11] Агеев В.Н., Бурмистрова О.П., Кузнецов Ю.А. // ФТТ. 1987. Т. 29. В. 6. C. $1740-1746$.

[12] Gall N.R., Rut'kov E.V., Tontegode A.Ya. // Int. J. Mod. Phys. B. 1997. V. 11. N 16. P. $1865-1911$.

[13] Rut'kov E.V., Gall N.R. // Physics and applications of graphene - experiments / Ed. S. Mikhailov. Intech. Open Access Publ., 2011. P. 209-292.

[14] Tontegode A.Ya. // Progr. Surf. Sci. 1991. V. 38. N 3-4. P. 201-429.

Письма в ЖТФ, 2018, том 44, вып. 12 
[15] Zhang H., Fu Q., Cui Y., Tan D., Bao X. // J. Phys. Chem. C. 2009. V. 113. N 19. P. $8296-8301$.

[16] Grånäs E., Knudsen J., Schröder U.A., Gerber T., Busse C., Arman M.A., Schulte K., Andersen J.N., Michely T. // ACS Nano. 2012. V. 6. N 11. P. 99519963.

[17] Larciprete R., Ulstrup S., Lacovig P., Dalmiglio M., Bianchi M., Mazzola F., Hornekaer L., Orlando F., Baraldi A., Hofmann P., Lizzit S. // ACS Nano. 2012. V. 6. N 11. P. 9551-9558.

[18] Starodub E., Bartelt N.C., McCarty K.F. // J. Phys. Chem. C. 2010. V. 114. N 11. P. 5134-5140.

[19] Klusek Z., Kozlowski W., Waqar Z., Datta S., Burnell-Gray J.S., Makarenko I.V., Gall N.R., Rut'kov E.V., Tontegode A.Ya., Titkov A.N. // Appl. Surf. Sci. 2005. V. 252. N 5. P. 1221-1227.

[20] Вакар З., Галль Н.Р., Макаренко И.В., Рутьков Е.В., Титков А.Н., Тонтегоде А.Я., Усубов М.М. // Поверхность. 1999. № 7. С. 39-51.

[21] Зандберг Э.Я., Ионов Н.И. Поверхностная ионизация. М.: Наука, 1969. $432 \mathrm{c}$.

[22] Рутьков Е.В., Тонтегоде А.Я. // УФН. 1993. Т. 163. № 11. С. 57-74.

[23] Rut'kov E.V., Gall N.R. // Physics and applications of graphene - experiments / Ed. S. Mikhailov. Intech. Open Access Publ., 2011. P. 293-326.

[24] Xie Y., Sherwood P.M.A. // Surf. Sci. Spectra. 1992. V. 1. N 4. P. 367-372.

[25] Анализ поверхности методами оже- и рентгеновской фотоэлектронной спектроскопии / Под ред. Д. Бриггса, М.П. Сиха. М.: Мир, 1987. С. 570.

[26] Добрецов Л.Н., Гамаюнова М.В. Эмиссионная электроника. М.: Наука, 1966. $564 \mathrm{c}$.

[27] Рутьков Е.В., Галль Н.Р. // Письма в ЖЭТФ. 2014. Т. 100. В. 10. С. 708-711. 